\title{
An airway exchange catheter facilitates removal of the intubating laryngeal airway after tracheal intubation in children
}

\author{
Narasimhan Jagannathan, MD • Ryan J. Kozlowski, BS
}

Received: 7 July 2010/ Accepted: 30 July 2010/Published online: 12 August 2010

(c) Canadian Anesthesiologists' Society 2010

\section{To the Editor,}

When encountering patients with difficult airways in pediatric anesthesia, clinicians have the option of using a supraglottic airway device as a conduit for tracheal intubation. The Laryngeal Mask Airway (LMA) Classic ${ }^{\mathrm{TM}}$ (LMA North America; San Diego, CA, USA) is the conduit used most commonly for tracheal intubation in the pediatric population. However, numerous challenges arise when the LMA is used to facilitate intubation with an endotracheal tube (ETT), especially during removal of the LMA following successful intubation. ${ }^{1}$ In particular, the airway tube of the LMA can be as long as the ETT, making it difficult to maintain control of the ETT while removing the LMA. Several techniques that decrease the likelihood of accidental extubation of the ETT during removal of the LMA have been devised and reported in the literature. These techniques include the use of a long ETT, a double ETT assembly, shortening or splitting the shaft of the LMA, or leaving the LMA in place for the duration of surgery. ${ }^{2}$ These techniques are all effective yet imperfect solutions to a procedure commonly encountered in a patient with a difficult airway.

The air- $\mathrm{Q}^{\mathrm{TM}}$ intubating laryngeal airway $\left(\mathrm{ILA}^{\mathrm{TM}}\right)$ (Cookgas LLC; St. Louis, MO, USA) is a newer supraglottic airway device that holds several advantages over the LMA when used to facilitate tracheal intubation in the pediatric population. Specifically, the airway tube of the ILA is shorter and wider than the LMA, which allows for greater control of the ETT and unhindered passage of the pilot balloon during removal of the ILA. ${ }^{1}$ At our

N. Jagannathan, MD $(\bowtie) \cdot$ R. J. Kozlowski, BS

Children's Memorial Hospital, Northwestern University's

Feinberg School of Medicine, Chicago, IL, USA

e-mail: simjag2000@yahoo.com institution, we have intubated the tracheas of hundreds of patients successfully by using the ILA as a conduit for tracheal intubation. It has been noted that the shorter airway tube length greatly facilitates distal control of the ETT and subsequent removal of the ILA after intubation. Unlike the LMA, the ILA has a custom removal stylet that can be used to stabilize the ETT during removal of the ILA device. However, if the manufacturer's removal stylet is not available or if the clinician is not comfortable with its use, we propose the use of an airway exchange catheter (AEC) (Cook Medical, Bloomington, IN, USA) to facilitate removal of the ILA (Figure). Use of an AEC during removal of the ILA offers advantages to the clinician who otherwise might be hesitant to remove the ILA after tracheal intubation. First, placement of the AEC maintains the ability to supply supplemental oxygen into the trachea and diminishes the possibility of oxygen desaturation. ${ }^{3}$ Second, the AEC provides a means for guided reintubation if the ETT is dislodged inadvertently during removal of the ILA device.

Generally, the smaller-sized ILAs (1.0 and 1.5) are short enough to facilitate gaining both proximal and distal control of the ETT during removal of the ILA. If an AEC is used, the clinician could cede control of the ETT once its proximal end is flush with the ILA and still retain proximal control of the AEC to ensure it remains in the trachea. The clinician can then remove the ILA until distal control of the ETT is possible, even if outside the patient's mouth, and then confirm tracheal depth and reintubate over the AEC if necessary.

Another potential technique that has been described for tracheal intubation through the LMA is to leave the fibreoptic bronchoscope within the trachea while removing the LMA, then to advance the ETT down the bronchoscope into the trachea. ${ }^{2}$ This method is beneficial, as no additional 

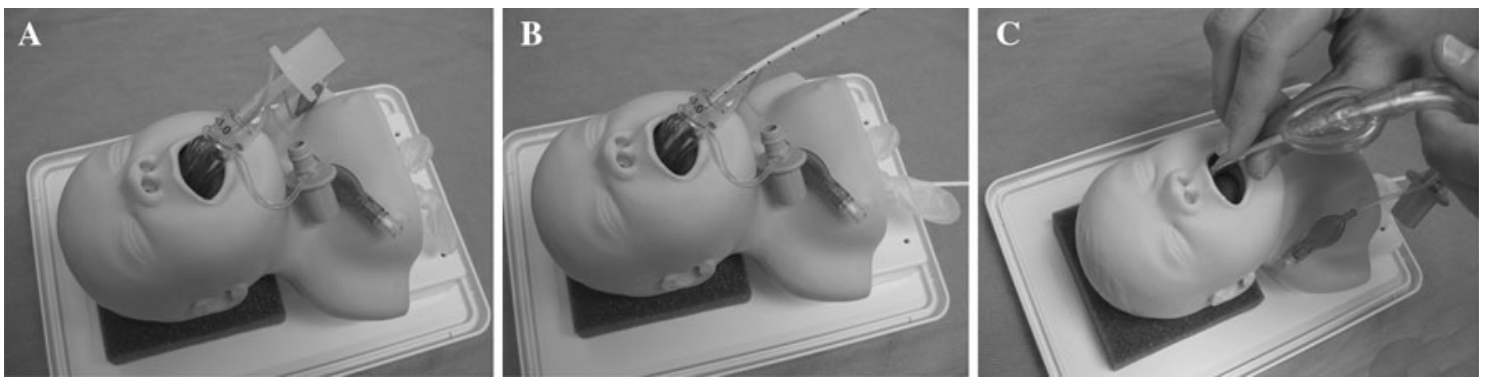

Figure Use of an airway exchange catheter (AEC) to facilitate removal of the endotracheal tube (ETT) after tracheal intubation using the air- $\mathrm{Q}^{\mathrm{TM}}$ intubating laryngeal airway (ILA). (A) ETT in position after placement through the ILA. (B) The AEC has been inserted through the ETT after the 15-mm ETT adapter has been removed. The ETT itself remains within the lumen of the ILA. The clinician has the

equipment is necessary, but some pediatric-sized bronchoscopes do not have side ports to facilitate oxygen administration, and the bronchoscope and its attachments may be more cumbersome than an AEC.

In our practice, we have used the AEC as a guide to remove the ILA in a patient with massive pulmonary edema and an unstable cervical spine. We used the ILA to rescue the airway and then used it as a conduit for blind tracheal intubation. We chose to use an AEC because a removal stylet or a fibreoptic bronchoscope was not readily available, and such a tenuous patient needed continuous oxygenation.

In summary, it is convenient to use an AEC as a substitute for the ILA manufacturer's stabilizing rod because an AEC is readily available at most institutions, and many clinicians are already familiar with its use. Airway exchange catheters are also available for most pediatric ETT sizes (Table). This is of particular importance in the management of the difficult airway where the initial securing of the airway may have been challenging and other means of intubation may prove to be problematic or challenging. If migration of the ETT were to occur upon removal of the ILA, the standard centimetre markings on both the AEC and the ETT could be utilized to determine correct placement and tracheal depth. Additionally, the ability to deliver supplemental oxygen through the AEC during removal of the ILA could be of particular benefit in the pediatric population due to their increased oxygen consumption and decreased oxygen reserve. ${ }^{4}$ Finally, delivery of oxygen via the AEC should appeal to inexperienced clinicians who wish to minimize disconnect time from the circuit while learning how to remove the ILA after tracheal intubation. option of connecting the proximal end of the AEC to the ventilation circuit with the provided 15-mm AEC Rapi-Fit adapter to provide oxygen during ILA removal. (C) The ETT is then adjusted over the AEC to ensure correct placement and appropriate tracheal depth using its markings as a guide

Table Specifications for airway exchange catheters commonly used in pediatric patients

\begin{tabular}{llll}
\hline $\begin{array}{l}\text { Catheter } \\
\text { Size (fr) }\end{array}$ & $\begin{array}{l}\text { Catheter } \\
\text { Length } \\
(\mathrm{cm})\end{array}$ & $\begin{array}{l}\text { Catheter internal } \\
\text { Diameter }(\mathrm{mm})\end{array}$ & $\begin{array}{l}\text { For use with endotracheal } \\
\text { tube Internal diameter } \\
(\mathrm{mm})\end{array}$ \\
\hline 8 & 45 & 1.6 & $3.0-3.5$ \\
11 & 83 & 2.3 & $4.0-4.5$ \\
14 & 83 & 3 & $5.0-6.5$ \\
\hline
\end{tabular}

$\mathrm{fr}=$ French size

Competing interests None declared.

Disclosure The ILA/air- $\mathrm{Q}^{\mathrm{TM}}$ devices used were generously provided by the manufacturer (Cookgas LLC; St. Louis, MO, USA). None of the authors has any affiliations that may be perceived to be conflicts of interest with the submitted material.

\section{References}

1. Jagannathan $N$, Roth AG, Sohn LE, Pak TY, Amin S, Suresh S. The new air-Q intubating laryngeal airway for tracheal intubation in children with anticipated difficult airway: a case series. Paediatr Anaesth 2009; 19: 618-22.

2. Ellis DS, Potluri PK, O'Flaherty JE, Baum VC. Difficult airway management in the neonate: a simple method of intubating through a laryngeal mask airway. Paediatr Anaesth 1999; 9: 460-2.

3. Wise-Faberowski L, Nargozian C. Utility of airway exchange catheters in pediatric patients with a known difficult airway. Pediatr Crit Care Med 2005; 6: 454-6.

4. Weiss M, Gerber AC, Schmitz A. Continuous ventilation technique for laryngeal mask airway (LMA) removal after fiberoptic intubation in children. Paediatr Anaesth 2004; 14: 936-40. 